\title{
A Comparison of the Adjustable Ranges of Inspiratory Pressurization During Pressure Controlled Continuous Mandatory Ventilation of 5 ICU Ventilators
}

\author{
Yukiko Koyama MD PhD, Akinori Uchiyama MD PhD, Junko Yoshida MD, \\ Takeshi Yoshida MD PhD, Tomonori Yamashita MD, and Yuji Fujino MD PhD
}

\begin{abstract}
BACKGROUND: Faster inspiratory pressurization can improve patient-ventilator synchrony and reduce the patient's work of breathing during pressure controlled continuous mandatory (PCCMV) ventilation. The characteristics of the pressurization ramp settings are not standardized across ventilators from different manufacturers. We performed a bench test of 5 models of ICU ventilators to examine the effects of pressurization ramp settings on the actual pressurization. METHODS: A twin-bellows lung model was used, in which one bellow simulates inspiratory muscle activity and the other simulates an adult normal lung model. We made the inspiratory effort by changing the tidal volume of the inspiratory muscle bellow. The effect of pressurization ramp settings on the performance of each ventilator was examined at 3 inspiratory effort levels (ie, none, ordinary, and strong). The pressurization ramp was set at 4 or 5 evenly divided steps from the minimum to maximum for each ventilator. The following parameters were measured: tidal volume, mean airway pressure, maximal inspiratory flow, time to maximal flow, and pressure-time products at $0.3 \mathrm{~s}\left(\mathrm{PTP}_{0.3}\right)$ and $0.5 \mathrm{~s}\left(\mathrm{PTP}_{0.5}\right)$ from the beginning of inspiration. $\mathrm{PTP}_{0.3}$ and $\mathrm{PTP}_{0.5}$ indicated levels of inspiratory pressurization. RESULTS: A proportional increase in $\mathbf{P T P}_{0.3}$ and $\mathbf{P T P}_{0.5}$ was observed with an increase in the pressurization ramp settings of the recent models of ventilators. PTP $_{0.3}$ and PTP $_{0.5}$ at ordinary and strong effort levels were similar in the recent models of ventilators. The actual adjustable ranges of $\mathbf{P T P}_{0.3}$ and $\mathbf{P T P}_{0.5}$ associated with change in the pressurization ramp settings differed between the 5 ventilators. CONCLUSIONS: The adjustable ranges of the pressurization were largely different among the different types of ventilators. The actual absolute inspiratory pressurization during PC-CMV varied between the different ventilators even at similar pressurization ramp settings. Users should be mindful of the differences in the pressurization ramp settings. Key words: assisted ventilation; pressure-controlled ventilation; inspiratory pressurization; pressurization ramp setting; rise time; ventilator performance; inspiratory effort. [Respir Care 2018;63(7):849-858. @ 2018 Daedalus Enterprises]
\end{abstract}

\section{Introduction}

The PC-CMV mode is used in critically ill patients with respiratory failure. Patients in need of assisted ventilation require appropriate synchronization of the ventilator with their inspiratory effort. In patient-triggered mode, a ventilator should quickly detect a patient's inspiratory effort and match the inspiratory flow to the patient's requirement; however, patient-ventilator asynchrony during the

\footnotetext{
A version of this article was presented by Dr Koyama at the American Thoracic Society Conference, held May 15-20, 2015, in Denver, Colorado.
}

The authors report no conflicts of interest. 
actual respiratory care of patients in the ICU occurs frequently. ${ }^{1,2}$ Mismatch between the initial inspiratory flow and the patient's requirement is a cause of patient-ventilator asynchrony. ${ }^{3-5}$ The speed of inspiratory pressurization has a clinically relevant impact on the patient's work

See the Related Editorial on Page 936

of breathing,,$^{3,5-9}$ which should be reduced using high inspiratory pressurization. Therefore, comparisons of inspiratory pressurization among different ventilator types have been performed in previous studies to evaluate ventilator performance. ${ }^{10-15}$ These studies have demonstrated that the function of inspiratory pressurization varies among ventilators. Although some recently developed ventilators incorporate an adjustable inspiratory pressurization ramp functionality, differences in pressurization still exist, even at the fastest pressurization ramp setting of each ventilator. If higher pressurization by faster inspiratory flow is applied to patients with high impedance, an overshoot of the airway pressure is likely to occur. ${ }^{16}$ Previous studies have demonstrated that improvement in patient comfort may not necessarily be achieved using the lowest and highest pressurization ramp settings. ${ }^{3,4}$ Therefore, differences in pressurization may markedly affect the clinical performance of ventilators during assisted ventilation. One reason cited by users for difficulty in operating adjustable pressurization ramps is that the characteristics of the pressurization ramp settings are completely different among ventilators.

Although pressurization functionality in pressure support ventilation has been studied in both patient and lung models, few studies have evaluated pressurization in the PC-CMV mode. ${ }^{17}$ The function of pressure support ventilation is largely dependent on the setting of flow cycle criteria. We assessed the effects of the inspiratory pressurization settings in the PC-CMV mode for a more accurate characterization of these settings. In this mode, the inspiratory time is determined by the users. We aimed to compare the inspiratory pressurization functionality in the PC-CMV mode of 5 recent ICU ventilators using a bench test. We examined the performance of the ventilators at 3 different inspiratory effort levels at 4 or 5 pressurization ramp settings.

Correspondence: Akinori Uchiyama MD PhD, Department of Anesthesiology and Intensive Care Medicine, Osaka University Graduate School of Medicine, Yamadaoka 2-15, Suita, Osaka Pref., 565-0871, Japan. E-mail: auchiyama@hp-icu.med.osaka-u.ac.jp.

DOI: $10.4187 /$ respcare. 05286

\section{QUICK LOOK}

\section{Current knowledge}

Inspiratory pressurization is important for resolving the problem of patient-ventilator asynchrony. Modern ventilators allow the adjustment of pressurization ramp settings to calibrate inspiratory pressurization. However, little knowledge about pressurization ramp settings is available.

\section{What this paper contributes to our knowledge}

The adjustable ranges of the pressurization were largely different among the different types of ventilators. The actual absolute inspiratory pressurization in the PCCMV mode differed among the ventilators, even at similar pressurization ramp settings. Although pressurization was amenable to control by adjusting pressurization ramp settings, users should be careful of the differences in the pressurization ramp settings in different ventilators.

\section{Methods}

We compared 5 ventilators: the Puritan Bennet 980 (Covidien, Boulder, Colorado), Servo-u (Maquet, Rastatt, Germany), Evita Infinity V500 (Dräger Medical, Lübeck, Germany), Hamilton G5 (Hamilton Medical, Rhäzüns, Switzerland), and Avea (CareFusion, San Diego, California). The study was performed at the Department of Anesthesiology and Intensive Care Medicine, Osaka University Graduate School of Medicine in Osaka, Japan.

\section{Simulation System}

A twin-bellows lung model (Dual Adult TTL, Michigan Instruments, Grand Rapids, Michigan) was used for the experiment, which is the same as that used for the simulation of spontaneous breathing in a previous study. ${ }^{18}$ In this model, one bellow simulates inspiratory muscle activity, and the other simulates a lung model. The bellows were connected to each other to simulate spontaneous breathing. The inspiratory muscle bellow, for which the compliance was set at $20 \mathrm{~mL} / \mathrm{cm} \mathrm{H}_{2} \mathrm{O}$, was ventilated by the Hamilton G5. The compliance and airway resistance of the lung model bellow were set at $50 \mathrm{~mL} / \mathrm{cm} \mathrm{H}_{2} \mathrm{O}$ and $5 \mathrm{~cm} \mathrm{H}_{2} \mathrm{O} / \mathrm{L} / \mathrm{s}$, respectively. The target ventilator was connected to the lung model bellow via an endotracheal tube (ETT) with an 8-mm internal diameter, a heat moisture exchanger (DAR Hygrobac S, Covidien), and a standard ventilator circuit (DAR adult ordinary circuit, Covidien). Flow was measured using a pneumotachograph (model 


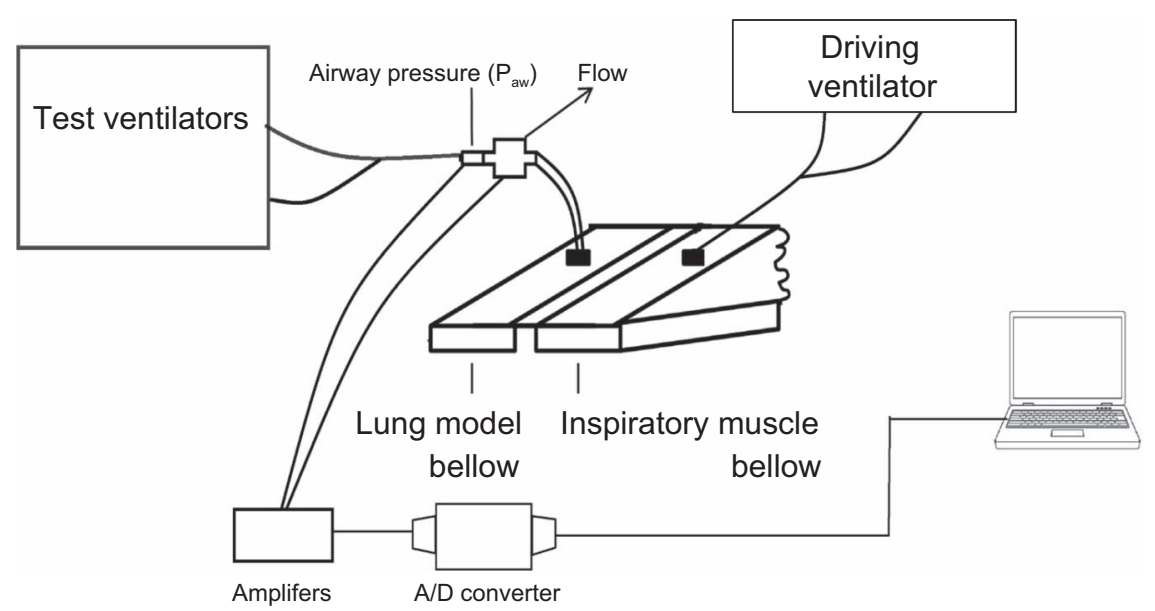

Fig. 1. Experimental set up. A driving ventilator was connected to the inspiratory muscle chamber. Test ventilators were connected to the test chamber via an endotracheal tube. Airway pressure and flow were measured at the proximal end of the endotracheal tube. $A / D=a n-$ alogue-to-digital.

4700; Hans Rudolph, Kansas City, Missouri) placed at the proximal end of the ETT, a differential pressure transducer (TP602T; Nihon Kohden, Tokyo, Japan), and an amplifier (AR601G; Nihon Kohden). Airway pressure $\left(\mathrm{P}_{\mathrm{aw}}\right)$ was also measured using a differential pressure transducer (TP603T) and an amplifier at the proximal end of the ETT. Signals from the amplifiers were recorded at a frequency of $100 \mathrm{~Hz}$ and analyzed using a data acquisition system (WINDAQ, Dataq Instruments, Akron, Ohio) (Fig. 1).

We studied 3 inspiratory effort levels (ie, none, ordinary, and strong). The inspiratory muscle bellow did not work at an inspiratory effort setting of none. To simulate an inspiratory breathing effort, the Hamilton G5 of the inspiratory muscle bellow was set at the following settings: assist control mode with volume-control breath, sinusoidal flow pattern, $5 \mathrm{~cm} \mathrm{H}_{2} \mathrm{O}$ PEEP, and a ventilator rate of $24 / \mathrm{min}$. We set inspiratory time at $0.8 \mathrm{~s}$ and $0.6 \mathrm{~s}$, and tidal volume at $300 \mathrm{~mL}$ and $600 \mathrm{~mL}$ to create ordinary and strong inspiratory effort levels, respectively. Peak flows at these settings were $27.7 \mathrm{~L} / \mathrm{min}$ and $73.2 \mathrm{~L} / \mathrm{min}$, respectively, and the airway occlusion pressure at $0.1 \mathrm{~s}$ was $4.1 \mathrm{~cm} \mathrm{H}_{2} \mathrm{O}$ and $9.7 \mathrm{~cm} \mathrm{H}_{2} \mathrm{O}$, respectively.

Test ventilators were set as follows: assist-control PC-CMV mode with inspiratory time: $1.0 \mathrm{~s}$, pressure control: $15 \mathrm{~cm} \mathrm{H}_{2} \mathrm{O}$, ventilation frequency: $15 / \mathrm{min}$, PEEP: $5 \mathrm{~cm} \mathrm{H}_{2} \mathrm{O}$, and inspiratory flow-triggering sensitivity: $2 \mathrm{~L} / \mathrm{min}$. Because the Evita Infinity V500 uses an arbitrary unit instead of L/min, the inspiratory flow-triggering sensitivity was set at 2 arbitrary units of flow trigger. The pressurization ramp was set at 5 steps evenly divided from the minimum to the maximum for each ventilator (PB 980: 1\%, 25\%, 50\%, 75\%, and 100\%; Servo-u: 0.4, 0.3, 0.2, 0.1, and $0 \mathrm{~s}$; Evita Infinity V500: 1, 0.75, 0.5, 0.25, and $0 \mathrm{~s}$; Avea: 9, 7, 5, 3, and 1 arbitrary unit). Although the maximum pressurization ramp setting of the Evita Infinity V500 is $2.0 \mathrm{~s}$, a setting that exceeds the inspiratory time is not applicable. Therefore, we set the maximum pressurization setting at $1.0 \mathrm{~s}$. Because it is difficult to evenly divide the range of the Hamilton G5 into 5 steps, the pressurization ramp was set at 4 steps $(0.2,0.15,0.1$, and $0.05 \mathrm{~s})$.

\section{Protocol}

The following parameters were used to assess the assist function at the early inspiratory phase, as described in previous reports ${ }^{10-15}$ (Fig. 2): maximum inspiratory flow $\left(\dot{\mathrm{V}}_{\max }\right)$, time from beginning of inspiratory flow to maximum flow $\left(\mathrm{T}_{\max }\right)$, and pressure-time product at 0.3 and $0.5 \mathrm{~s}\left(\mathrm{PTP}_{0.3}\right.$ and $\mathrm{PTP}_{0.5}$; values were obtained by integrating $\mathrm{P}_{\mathrm{aw}}$ tracings at $0.3 \mathrm{~s}$ and $0.5 \mathrm{~s}$ from the beginning of the inspiratory phase). Tidal volume $\left(\mathrm{V}_{\mathrm{T}}\right)$ and mean airway pressure in the inspiratory phase (mean $\mathrm{P}_{\mathrm{aw}}\left[\overline{\mathrm{P}}_{\mathrm{aw}}\right]$ ) were also measured.

\section{Data Analysis and Statistics}

For each parameter, mean values from 5 consecutive breaths after attaining the steady state are presented. A 2-way factorial analysis of variance test was used to assess the effects of pressurization ramp settings of each ventilator at 3 effort levels. The pressurization function of the 5 ventilators was compared using a 1-way analysis of variance test at the maximum and minimum pressurization ramp settings with strong effort level. The pressurization function of the 5 ventilators was compared using 1-way analysis of variance test at none, ordinary, and strong effort levels with the maximum pressurization ramp setting. If statistically significant 


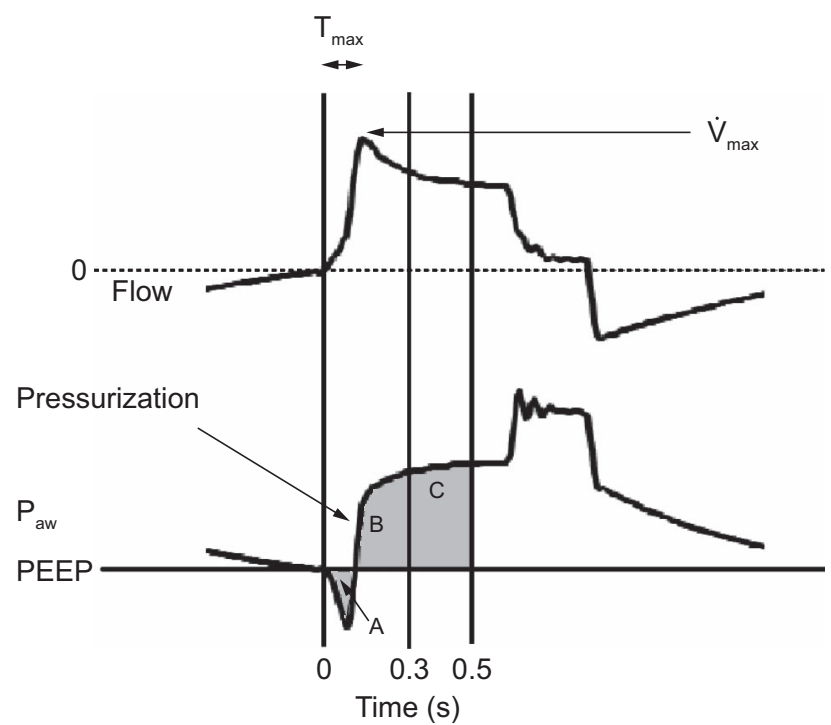

Fig. 2. Representative flow (top) and airway pressure (bottom) tracings and the definition of the parameters. $T_{\max }=$ the time from the beginning of the inspiratory phase to the maximum flow; $\dot{\mathrm{V}}_{\max }=$ maximum inspiratory flow; $\mathrm{PTP}_{0.3}$ and $\mathrm{PTP}_{0.5}=$ pressuretime products of airway pressure at $0.3 \mathrm{~s}$ and $0.5 \mathrm{~s}$, respectively, from the beginning of the inspiratory phase. The values of PTP $_{0.3}$ and PTP $_{0.5}$ are derived from the area of $(B-A)$ and the area of $(B+C-A)$, respectively. $P_{a w}=$ airway pressure. Gray shaded area denotes PTP.

differences existed, multiple post hoc comparisons were performed using Tukey's honestly significant difference test. $P$ values $<.05$ were considered statistically significant. Statistical analysis was performed using statistical software (JMP pro 12.2; SAS Institute, Chicago, Illinois).

\section{Results}

The effects of pressurization ramp settings at the 3 inspiratory effort levels for each ventilator are shown in Figure 3 and Table 1. $\mathrm{PTP}_{0.3}, \mathrm{PTP}_{0.5}$, and $\overline{\mathrm{P}}_{\mathrm{aw}}$ were lower at ordinary and strong effort levels than at the none effort level for all ventilators. The 4 newly developed ventilators (PB 980, Servo-u, Evita Infinity V500, and Hamilton G5) exhibited similar performance. As the pressurization ramp settings were increased, $\mathrm{PTP}_{0.3}$, $\mathrm{PTP}_{0.5}$, and $\overline{\mathrm{P}}_{\mathrm{aw}}$ increased. Thus, the relationship of $\mathrm{PTP}_{0.3}, \mathrm{PTP}_{0.5}$, and $\overline{\mathrm{P}}_{\mathrm{aw}}$ with the pressurization ramp settings was proportional. Although $\mathrm{PTP}_{0.3}$ at strong effort level was lower than $\mathrm{PTP}_{0.3}$ at the ordinary effort level at the lower pressurization ramp settings, $\mathrm{PTP}_{0.3}$ at ordinary and strong effort levels were similar at the higher pressurization ramp settings. $\mathrm{PTP}_{0.5}$ and $\overline{\mathrm{P}}_{\mathrm{aw}}$ at strong and ordinary effort levels were similar. $\mathrm{V}_{\mathrm{T}}$ and $\dot{V}_{\text {max }}$ at the ordinary and none effort levels were similar, and these values were lower than the $\mathrm{V}_{\mathrm{T}}$ and $\dot{\mathrm{V}}_{\max }$ val- ues at strong effort level. The $\mathrm{T}_{\max }$ values at strong and ordinary effort levels were similar and shorter than the $\mathrm{T}_{\max }$ value at the none effort level with the PB 980 and Hamilton G5 equipment. $T_{\max }$ values at the none and ordinary effort levels were similar and longer than $\mathrm{T}_{\max }$ values at strong effort levels with the Servo-u and Evita Infinity V500 ventilators. The characteristics of the Avea ventilator were different from those of others, in that the slopes of $\mathrm{PTP}_{0.3}, \mathrm{PTP}_{0.5}$, and $\overline{\mathrm{P}}_{\mathrm{aw}}$ against pressurization ramp settings were not very steep. In the Avea ventilator, although the $\overline{\mathrm{P}}_{\mathrm{aw}}$ was smaller at the strong effort level than at the ordinary effort level, $\mathrm{PTP}_{0.3}$ and $\mathrm{PTP}_{0.5}$ were higher at the strong effort level than at the ordinary effort level at higher pressurization ramp settings. $\mathrm{V}_{\mathrm{T}}$ at all setting levels was not very different with the Avea ventilator.

\section{Comparison of the Pressurization Function Between the 5 Ventilators}

$\mathrm{PTP}_{0.3}, \mathrm{PTP}_{0.5}$, and $\overline{\mathrm{P}}_{\mathrm{aw}}$ at the maximum and minimum pressurization ramp settings with strong effort level are shown in Figure 4. Significant differences were observed between the ventilators at both pressurization ramp settings. The $\mathrm{PTP}_{0.3}, \mathrm{PTP}_{0.5}$, and $\overline{\mathrm{P}}_{\mathrm{aw}}$ for the PB 980, Servo-u, and Evita Infinity V500 were larger than those of others at the maximum settings. Because the $\mathrm{PTP}_{0.3}$, $\mathrm{PTP}_{0.5}$, and $\overline{\mathrm{P}}_{\mathrm{aw}}$ for Evita Infinity V500 were the smallest at the minimum setting, it tended to have the largest adjustable range of pressurization.

$\mathrm{PTP}_{0.3}, \mathrm{PTP}_{0.5}$, and $\overline{\mathrm{P}}_{\mathrm{aw}}$ of the maximum pressurization ramp settings at none, ordinary, and strong effort levels are shown in Figure 5. Significant differences existed among the ventilators at the 3 effort levels. The $\mathrm{PTP}_{0.3}, \mathrm{PTP}_{0.5}$, and $\overline{\mathrm{P}}_{\mathrm{aw}}$ for the Avea machine was lower than those of other ventilators. The $\mathrm{PTP}_{0.3}$ for the Hamilton G5 was also slightly lower than those for the PB 980, Servo-u, and Evita Infinity V500 ventilators. The thre3 newly developed ventilators (PB 980, Servo-u, and Evita Infinity V500) exhibited a similar performance.

\section{Discussion}

We studied the performance of 5 ICU ventilators with different pressurization ramp settings at 3 different inspiratory effort levels. Inspiratory pressurization at ordinary and strong effort levels was not so different in these recent ICU ventilators. The relationship of actual pressurization with the pressurization ramp settings was proportional and controllable in these recent ventilators. The absolute adjustable range of pressurization was not similar among the ventilators. 

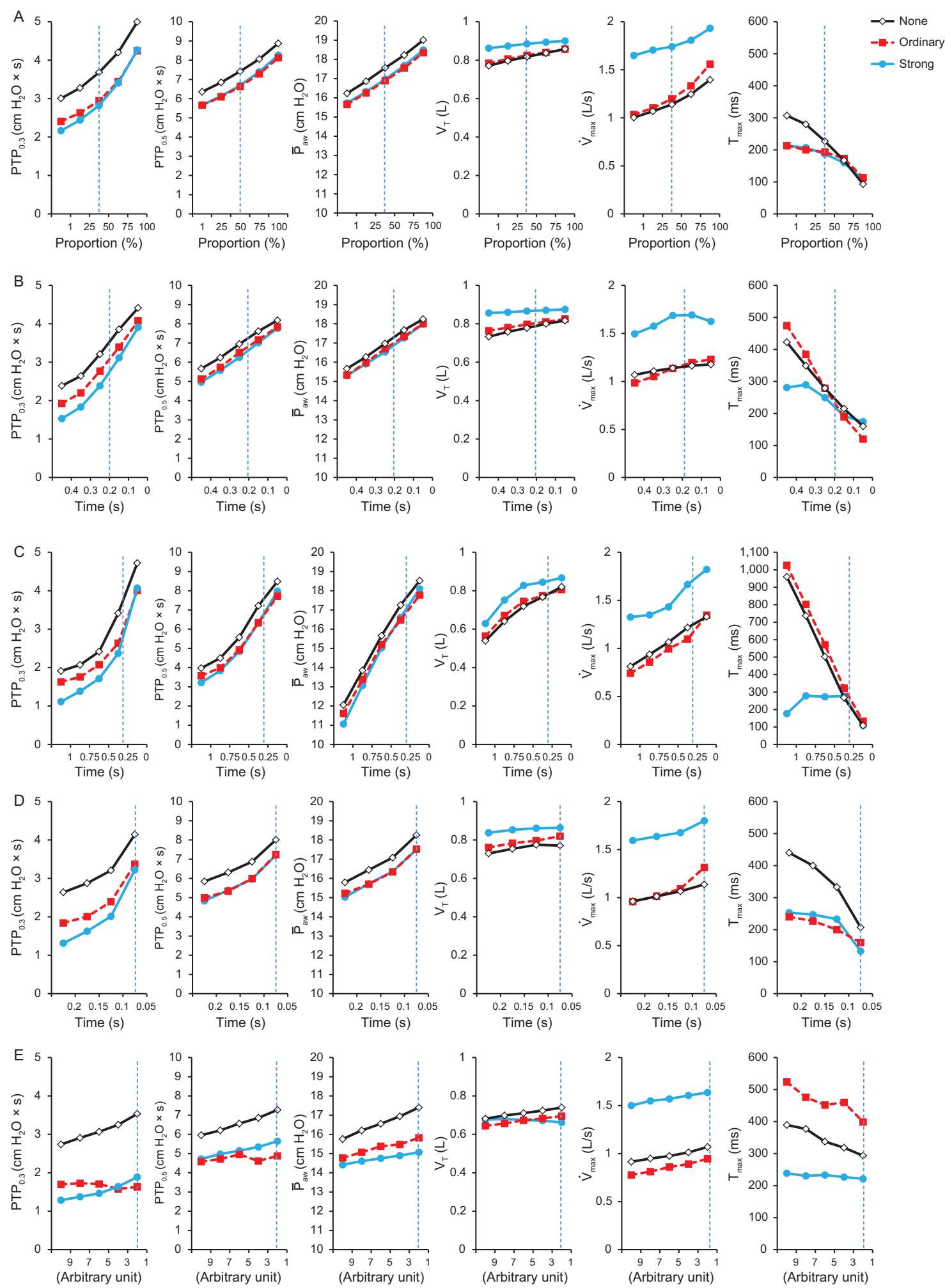

Fig. 3. Effects of pressurization ramp settings on pressure-time products (PTPs) of airway pressure $\left(P_{\text {aw }}\right)$ at $0.3 \mathrm{~s}\left(\mathrm{PTP}_{0.3}\right)$ and $0.5 \mathrm{~s}\left(\mathrm{PTP}_{0.5}\right)$ from the beginning of the inspiratory phase, mean inspiratory pressure (mean $\mathrm{P}_{\text {aw }}\left[\overline{\mathrm{P}}_{\text {awl }}\right)$, tidal volume $\left(\mathrm{V}_{T}\right)$, maximum inspiratory flow $\left(\dot{V}_{\max }\right)$, and the time from the beginning of the inspiratory phase to the maximum flow $\left(T_{\max }\right)$ of the 5 ventilators at none, ordinary, and strong levels of inspiratory efforts. (A) PB 980, (B) Servo-u, (C) Evita Infinity V500, (D) Hamilton G5, and (E) Avea. Because the distribution range for each setting was very small, the graphs only exhibit the mean values for each setting. The vertical dashed lines indicate the default pressurization ramp settings by the manufacturers. Both the pressurization ramp settings and the effort levels significantly affected every category in all the ventilators. 


\section{Comparison of Pressure Controlled Ventilation Modes}

Table 1. Measurement Data for PB 980, Servo-u, Evita Infinity V500, Hamilton G5, and Avea Ventilators

\begin{tabular}{|c|c|c|c|c|c|c|c|}
\hline $\begin{array}{c}\text { Inspiratory } \\
\text { Effort } \\
\text { Level }\end{array}$ & $\begin{array}{c}\text { Pressurization } \\
\text { Ramp } \\
\text { Settings }(\%)\end{array}$ & $\mathrm{PTP}_{0.3}\left(\mathrm{~cm} \mathrm{H}_{2} \mathrm{O} \times \mathrm{s}\right)$ & $\mathrm{PTP}_{0.5}\left(\mathrm{~cm} \mathrm{H}_{2} \mathrm{O} \times \mathrm{s}\right)$ & $\overline{\mathrm{P}}_{\mathrm{aw}}\left(\mathrm{cm} \mathrm{H}_{2} \mathrm{O}\right)$ & $\mathrm{V}_{\mathrm{T}}(\mathrm{mL})$ & $\dot{\mathrm{V}}_{\max }(\mathrm{L} / \mathrm{s})$ & $\mathrm{T}_{\max }(\mathrm{ms})$ \\
\hline
\end{tabular}

PB 980 (\% for pressurization ramp settings)

$\begin{array}{lrl}\text { None } & 1 & 2.17 \pm 0.04 \\ \text { None } & 25 & 2.44 \pm 0.04 \\ \text { None } & 50 & 2.83 \pm 0.07 \\ \text { None } & 75 & 3.41 \pm 0.05 \\ \text { None } & 100 & 4.27 \pm 0.05 \\ \text { Ordinary } & 1 & 2.41 \pm 0.05 \\ \text { Ordinary } & 25 & 2.63 \pm 0.03 \\ \text { Ordinary } & 50 & 2.95 \pm 0.03 \\ \text { Ordinary } & 75 & 3.44 \pm 0.07 \\ \text { Ordinary } & 100 & 4.25 \pm 0.03 \\ \text { Strong } & 1 & 3.01 \pm 0.04 \\ \text { Strong } & 25 & 3.28 \pm 0.03 \\ \text { Strong } & 50 & 3.69 \pm 0.03 \\ \text { Strong } & 75 & 4.20 \pm 0.04 \\ \text { Strong } & 100 & 5.00 \pm 0.03\end{array}$

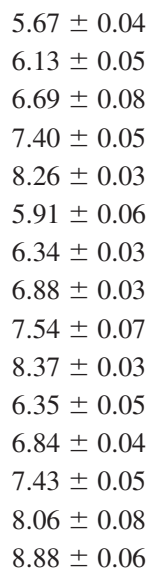

Servo-u (seconds for pressurization ramp settings)

$\begin{array}{lll}\text { None } & 0.4 & 1.53 \pm 0.03 \\ \text { None } & 0.3 & 1.84 \pm 0.02 \\ \text { None } & 0.2 & 2.39 \pm 0.03 \\ \text { None } & 0.1 & 3.11 \pm 0.06 \\ \text { None } & 0 & 3.91 \pm 0.05 \\ \text { Ordinary } & 0.4 & 1.93 \pm 0.03 \\ \text { Ordinary } & 0.3 & 2.20 \pm 0.02 \\ \text { Ordinary } & 0.2 & 2.77 \pm 0.02 \\ \text { Ordinary } & 0.1 & 3.39 \pm 0.03 \\ \text { Ordinary } & 0 & 4.08 \pm 0.03 \\ \text { Strong } & 0.4 & 2.39 \pm 0.03 \\ \text { Strong } & 0.3 & 2.64 \pm 0.01 \\ \text { Strong } & 0.2 & 3.21 \pm 0.01 \\ \text { Strong } & 0.1 & 3.85 \pm 0.01 \\ \text { Strong } & 0 & 4.42 \pm 0.02\end{array}$

Evita Infinity V500 (seconds for pressurization ramp settings)

$\begin{array}{lll}\text { None } & 1 & 1.11 \pm 0.06 \\ \text { None } & 0.75 & 1.39 \pm 0.02 \\ \text { None } & 0.5 & 1.72 \pm 0.07 \\ \text { None } & 0.25 & 2.37 \pm 0.04 \\ \text { None } & 0 & 4.07 \pm 0.05 \\ \text { Ordinary } & 1 & 1.63 \pm 0.01 \\ \text { Ordinary } & 0.75 & 1.76 \pm 0.01 \\ \text { Ordinary } & 0.5 & 2.08 \pm 0.06 \\ \text { Ordinary } & 0.25 & 2.63 \pm 0.05 \\ \text { Ordinary } & 0 & 4.01 \pm 0.06 \\ \text { Strong } & 1 & 1.91 \pm 0.01 \\ \text { Strong } & 0.75 & 2.07 \pm 0.02 \\ \text { Strong } & 0.5 & 2.42 \pm 0.02 \\ \text { Strong } & 0.25 & 3.42 \pm 0.05 \\ \text { Strong } & 0 & 4.72 \pm 0.03\end{array}$

$4.95 \pm 0.04$

$5.57 \pm 0.01$

$6.24 \pm 0.07$

$7.00 \pm 0.03$

$7.77 \pm 0.03$

$5.11 \pm 0.07$

$5.75 \pm 0.03$

$6.50 \pm 0.02$

$7.16 \pm 0.02$

$7.85 \pm 0.05$

$5.67 \pm 0.04$

$6.22 \pm 0.03$

$6.93 \pm 0.05$

$7.61 \pm 0.05$

$8.18 \pm 0.03$

$3.22 \pm 0.09$
$3.84 \pm 0.04$
$4.84 \pm 0.10$
$6.33 \pm 0.05$
$7.98 \pm 0.05$
$3.58 \pm 0.02$
$3.99 \pm 0.02$
$4.93 \pm 0.04$
$6.34 \pm 0.08$
$7.72 \pm 0.06$
$3.97 \pm 0.03$
$4.49 \pm 0.04$
$5.58 \pm 0.03$
$7.22 \pm 0.06$
$8.48 \pm 0.03$

$\begin{array}{llll}15.7 \pm 0.0 & 863 \pm 4 & 1.65 \pm 0.01 & 216 \pm 4 \\ 16.3 \pm 0.0 & 874 \pm 1 & 1.71 \pm 0.05 & 205 \pm 9 \\ 17.0 \pm 0.0 & 886 \pm 1 & 1.74 \pm 0.01 & 187 \pm 7 \\ 17.7 \pm 0.0 & 894 \pm 1 & 1.81 \pm 0.01 & 159 \pm 6 \\ 18.5 \pm 0.0 & 900 \pm 1 & 1.93 \pm 0.01 & 106 \pm 3 \\ 15.7 \pm 0.1 & 784 \pm 1 & 1.03 \pm 0.01 & 213 \pm 8 \\ 16.3 \pm 0.0 & 807 \pm 1 & 1.10 \pm 0.00 & 204 \pm 6 \\ 16.9 \pm 0.0 & 826 \pm 1 & 1.20 \pm 0.00 & 194 \pm 3 \\ 17.6 \pm 0.1 & 841 \pm 2 & 1.33 \pm 0.01 & 172 \pm 5 \\ 18.3 \pm 0.0 & 858 \pm 1 & 1.56 \pm 0.00 & 116 \pm 4 \\ 16.2 \pm 0.1 & 771 \pm 2 & 1.00 \pm 0.01 & 311 \pm 12 \\ 16.9 \pm 0.0 & 797 \pm 2 & 1.07 \pm 0.01 & 275 \pm 11 \\ 17.6 \pm 0.0 & 818 \pm 2 & 1.14 \pm 0.00 & 231 \pm 9 \\ 18.2 \pm 0.1 & 837 \pm 2 & 1.25 \pm 0.00 & 167 \pm 5 \\ 19.0 \pm 0.1 & 858 \pm 5 & 1.40 \pm 0.00 & 96 \pm 8\end{array}$

$15.3 \pm 0.0$

$15.9 \pm 0.0$

$16.5 \pm 0.1$

$17.3 \pm 0.0$

$18.0 \pm 0.0$

$15.3 \pm 0.0$

$16.0 \pm 0.0$

$16.7 \pm 0.0$

$17.3 \pm 0.0$

$18.0 \pm 0.0$

$15.7 \pm 0.0$

$16.3 \pm 0.0$

$17.0 \pm 0.0$

$17.7 \pm 0.0$

$18.2 \pm 0.0$

$857 \pm$

$860 \pm 1$

$1.50 \pm 0.00$

$1.58 \pm 0.02$

$866 \pm 0 \quad 1.69 \pm 0.01$

$871 \pm 1$

$875 \pm 1$

$764 \pm 1$

$1.69 \pm 0.01$

$1.63 \pm 0.01$

$0.98 \pm 0.00$

$781 \pm 2 \quad 1.05 \pm 0.00$

$797 \pm 1 \quad 1.14 \pm 0.00$

$811 \pm 1$

$825 \pm 1$

$1.20 \pm 0.00$

$1.23 \pm 0.00$

$733 \pm 1$

$1.07 \pm 0.00$

$758 \pm 1$

$1.11 \pm 0.00$

$778 \pm 1$

$1.14 \pm 0.00$

$800 \pm 1$

$1.16 \pm 0.00$

$1.18 \pm 0.00$

$281 \pm 9$

$289 \pm 3$

$249 \pm 8$

$192 \pm 9$

$174 \pm 3$

$475 \pm 6$

$384 \pm 6$

$279 \pm 6$

$189 \pm 3$

$120 \pm 7$

$423 \pm 12$

$349 \pm 6$

$279 \pm 12$

$215 \pm 9$

$160 \pm 5$

$11.1 \pm 0.1$

$629 \pm 4$

$1.33 \pm 0.01$

$1.35 \pm 0.01$

$13.1 \pm 0.1$

$15.0 \pm 0.1$

$752 \pm 2$

$828 \pm 3$

$845 \pm 1$

$1.43 \pm 0.00$

$1.67 \pm 0.00$

$18.1 \pm 0.0$

$11.6 \pm 0.0$

$867 \pm 2$

$1.82 \pm 0.01$

$0.74 \pm 0.00$

$0.86 \pm 0.00$

$671 \pm 1$

$1.00 \pm 0.00$

$15.2 \pm 0.0$

$745 \pm 1$

$774 \pm 7$

$1.10 \pm 0.01$

$1.35 \pm 0.02$

$17.8 \pm 0.1$

$12.1 \pm 0.0$

$13.9 \pm 0.0$

$15.7 \pm 0.0$

$17.3 \pm 0.1$

$18.5 \pm 0.0$

$806 \pm 6$

$540 \pm 1$

$641 \pm 2$

$719 \pm 2$

$768 \pm 5$

$820 \pm 26$

$0.81 \pm 0.00$

$0.94 \pm 0.00$

$1.07 \pm 0.01$

$1.22 \pm 0.07$

$1.33 \pm 0.01$
$177 \pm 4$

$279 \pm 3$

$273 \pm 5$

$277 \pm 4$

$108 \pm 3$

$1025 \pm 7$

$802 \pm 9$

$571 \pm 8$

$323 \pm 10$

$133 \pm 12$

$960 \pm 10$

$737 \pm 4$

$503 \pm 8$

$268 \pm 3$

$108 \pm 3$

(continued) 
Comparison of Pressure Controlled Ventilation Modes

Table 1. Continued

\begin{tabular}{|c|c|c|c|c|c|c|c|}
\hline $\begin{array}{l}\text { Inspiratory } \\
\text { Effort } \\
\text { Level }\end{array}$ & $\begin{array}{l}\text { Pressurization } \\
\text { Ramp } \\
\text { Settings (\%) }\end{array}$ & $\mathrm{PTP}_{0.3}\left(\mathrm{~cm} \mathrm{H}_{2} \mathrm{O} \times \mathrm{s}\right)$ & $\mathrm{PTP}_{0.5}\left(\mathrm{~cm} \mathrm{H}_{2} \mathrm{O} \times \mathrm{s}\right)$ & $\overline{\mathrm{P}}_{\mathrm{aw}}\left(\mathrm{cm} \mathrm{H} \mathrm{H}_{2} \mathrm{O}\right)$ & $\mathrm{V}_{\mathrm{T}}(\mathrm{mL})$ & $\dot{\mathrm{V}}_{\max }(\mathrm{L} / \mathrm{s})$ & $\mathrm{T}_{\max }(\mathrm{ms})$ \\
\hline \multicolumn{8}{|c|}{ Hamilton G5 (seconds for pressurization ramp settings) } \\
\hline None & 0.2 & $2.64 \pm 0.02$ & $5.84 \pm 0.03$ & $15.8 \pm 0.0$ & $730 \pm 0$ & $0.96 \pm 0.01$ & $431 \pm 38$ \\
\hline None & 0.15 & $2.88 \pm 0.02$ & $6.31 \pm 0.03$ & $16.4 \pm 0.0$ & $754 \pm 1$ & $1.01 \pm 0.01$ & $396 \pm 19$ \\
\hline None & 0.1 & $3.21 \pm 0.03$ & $6.87 \pm 0.03$ & $17.1 \pm 0.0$ & $775 \pm 0$ & $1.07 \pm 0.01$ & $344 \pm 26$ \\
\hline None & 0.05 & $4.14 \pm 0.03$ & $8.01 \pm 0.03$ & $18.3 \pm 0.0$ & $771 \pm 14$ & $1.14 \pm 0.02$ & $212 \pm 15$ \\
\hline Ordinary & 0.2 & $1.84 \pm 0.02$ & $5.00 \pm 0.02$ & $15.2 \pm 0.0$ & $761 \pm 3$ & $0.96 \pm 0.01$ & $236 \pm 6$ \\
\hline Ordinary & 0.15 & $2.00 \pm 0.09$ & $5.34 \pm 0.15$ & $15.7 \pm 0.2$ & $784 \pm 5$ & $1.02 \pm 0.02$ & $231 \pm 6$ \\
\hline Ordinary & 0.1 & $2.40 \pm 0.06$ & $5.99 \pm 0.07$ & $16.3 \pm 0.1$ & $796 \pm 1$ & $1.09 \pm 0.01$ & $207 \pm 14$ \\
\hline Ordinary & 0.05 & $3.37 \pm 0.04$ & $7.24 \pm 0.04$ & $17.5 \pm 0.0$ & $820 \pm 1$ & $1.31 \pm 0.00$ & $159 \pm 3$ \\
\hline Strong & 0.2 & $1.31 \pm 0.03$ & $4.83 \pm 0.04$ & $15.0 \pm 0.0$ & $837 \pm 3$ & $1.59 \pm 0.01$ & $253 \pm 15$ \\
\hline Strong & 0.15 & $1.63 \pm 0.05$ & $5.38 \pm 0.07$ & $15.7 \pm 0.1$ & $853 \pm 1$ & $1.64 \pm 0.01$ & $244 \pm 14$ \\
\hline Strong & 0.1 & $2.01 \pm 0.06$ & $5.96 \pm 0.06$ & $16.4 \pm 0.0$ & $861 \pm 1$ & $1.68 \pm 0.00$ & $236 \pm 14$ \\
\hline Strong & 0.05 & $3.22 \pm 0.05$ & $7.21 \pm 0.06$ & $17.5 \pm 0.0$ & $864 \pm 1$ & $1.80 \pm 0.01$ & $133 \pm 7$ \\
\hline \multicolumn{8}{|c|}{ Avea (arbitrary units for pressurization ramp settings) } \\
\hline None & 9 & $1.29 \pm 0.04$ & $4.73 \pm 0.04$ & $14.4 \pm 0.1$ & $677 \pm 6$ & $1.50 \pm 0.01$ & $239 \pm 6$ \\
\hline None & 7 & $1.38 \pm 0.05$ & $4.96 \pm 0.04$ & $14.6 \pm 0.1$ & $680 \pm 5$ & $1.55 \pm 0.01$ & $231 \pm 3$ \\
\hline None & 5 & $1.46 \pm 0.07$ & $5.13 \pm 0.03$ & $14.8 \pm 0.1$ & $676 \pm 6$ & $1.57 \pm 0.00$ & $233 \pm 23$ \\
\hline None & 3 & $1.64 \pm 0.03$ & $5.34 \pm 0.04$ & $14.9 \pm 0.0$ & $672 \pm 4$ & $1.61 \pm 0.04$ & $227 \pm 12$ \\
\hline None & 1 & $1.89 \pm 0.02$ & $5.66 \pm 0.04$ & $15.1 \pm 0.1$ & $662 \pm 6$ & $1.64 \pm 0.01$ & $221 \pm 11$ \\
\hline Ordinary & 9 & $1.70 \pm 0.06$ & $4.58 \pm 0.07$ & $14.7 \pm 0.1$ & $644 \pm 2$ & $0.78 \pm 0.00$ & $524 \pm 25$ \\
\hline Ordinary & 7 & $1.73 \pm 0.04$ & $4.73 \pm 0.06$ & $15.1 \pm 0.1$ & $657 \pm 2$ & $0.81 \pm 0.00$ & $476 \pm 6$ \\
\hline Ordinary & 5 & $1.71 \pm 0.17$ & $4.86 \pm 0.25$ & $15.4 \pm 0.2$ & $673 \pm 6$ & $0.86 \pm 0.02$ & $452 \pm 29$ \\
\hline Ordinary & 3 & $1.58 \pm 0.28$ & $4.81 \pm 0.36$ & $15.5 \pm 0.3$ & $683 \pm 1$ & $0.89 \pm 0.01$ & $460 \pm 27$ \\
\hline Ordinary & 1 & $1.63 \pm 0.36$ & $5.05 \pm 0.44$ & $15.8 \pm 0.3$ & $695 \pm 2$ & $0.95 \pm 0.01$ & $399 \pm 26$ \\
\hline Strong & 9 & $2.74 \pm 0.03$ & $5.96 \pm 0.05$ & $15.8 \pm 0.1$ & $682 \pm 2$ & $0.91 \pm 0.00$ & $389 \pm 22$ \\
\hline Strong & 7 & $2.91 \pm 0.07$ & $6.26 \pm 0.15$ & $16.2 \pm 0.2$ & $698 \pm 7$ & $0.95 \pm 0.02$ & $377 \pm 44$ \\
\hline Strong & 5 & $3.07 \pm 0.02$ & $6.55 \pm 0.03$ & $16.6 \pm 0.0$ & $711 \pm 0$ & $0.97 \pm 0.00$ & $337 \pm 20$ \\
\hline Strong & 3 & $3.25 \pm 0.02$ & $6.86 \pm 0.02$ & $16.9 \pm 0.0$ & $724 \pm 2$ & $1.01 \pm 0.00$ & $318 \pm 12$ \\
\hline Strong & 1 & $3.54 \pm 0.02$ & $7.28 \pm 0.01$ & $17.4 \pm 0.0$ & $740 \pm 3$ & $1.07 \pm 0.01$ & $293 \pm 14$ \\
\hline \multicolumn{8}{|c|}{$\begin{array}{l}\text { Data are presented as mean } \pm \mathrm{SD} \text {. } \\
\mathrm{PTP}_{0.3}, \mathrm{PTP}_{0.5}=\text { product pressure-time products at } 0.3 \text { and } 0.5 \mathrm{~s} \text { (values obtained by integrating airway pressure tracings at } 0.3 \text { and } 0.5 \mathrm{~s} \text { from the beginning of the inspiratory phase) } \\
\overline{\mathrm{P}}_{\text {aw }}=\text { mean airway pressure in the inspiration } \\
\mathrm{V}_{\mathrm{T}}=\text { tidal volume } \\
\dot{\mathrm{V}}_{\max }=\text { maximal inspiratory flow } \\
\mathrm{T}_{\max }=\text { time from beginning inspiratory phase to maximum flow }\end{array}$} \\
\hline
\end{tabular}

The parameters $\mathrm{PTP}_{0.3}$ and $\mathrm{PTP}_{0.5}$ used to assess the performance of inspiratory pressurization in this study have also been used in previous studies. ${ }^{10-15}$ Inspiratory pressurization was lower at ordinary and strong effort levels than at the none effort level of control ventilation. Older ventilators were reported to provide smaller levels of $\mathrm{PTP}_{0.3}$ and $\mathrm{PTP}_{0.5}$ at the strong effort level than that at the ordinary effort level. ${ }^{11}$ However, in this study, $\mathrm{PTP}_{0.3}$, which represented the earliest parameter of pressurization, was not significantly different at the strong and ordinary effort levels if the pressurization ramp setting was at an adequately high level. $\mathrm{PTP}_{0.5}$ at the strong effort level was similar to that at the ordinary effort level, which is consistent with the results of previous studies in which the latest ventilators were used. ${ }^{10,11,15}$ The observed differences between the old and the new ventilators are attributable to the advanced technology used in the latter.

Inspiratory pressurization is important for improving synchronization and reducing the patient's work of breathing. ${ }^{3,5-9}$ Appropriate pressurization increases patient comfort. Higher inspiratory pressurization is needed in case of higher inspiratory drive. In contrast, Chiumello et $\mathrm{al}^{3}$ found that both high and low pressure rise slopes increased discomfort and work of breathing. It is difficult to determine which pressurization level is optimal. The ability to change the pressurization ramp is useful to determine the appropriate setting. However, because the previous studies examined the performance of ventilators only at the maximum pressurization ramp 

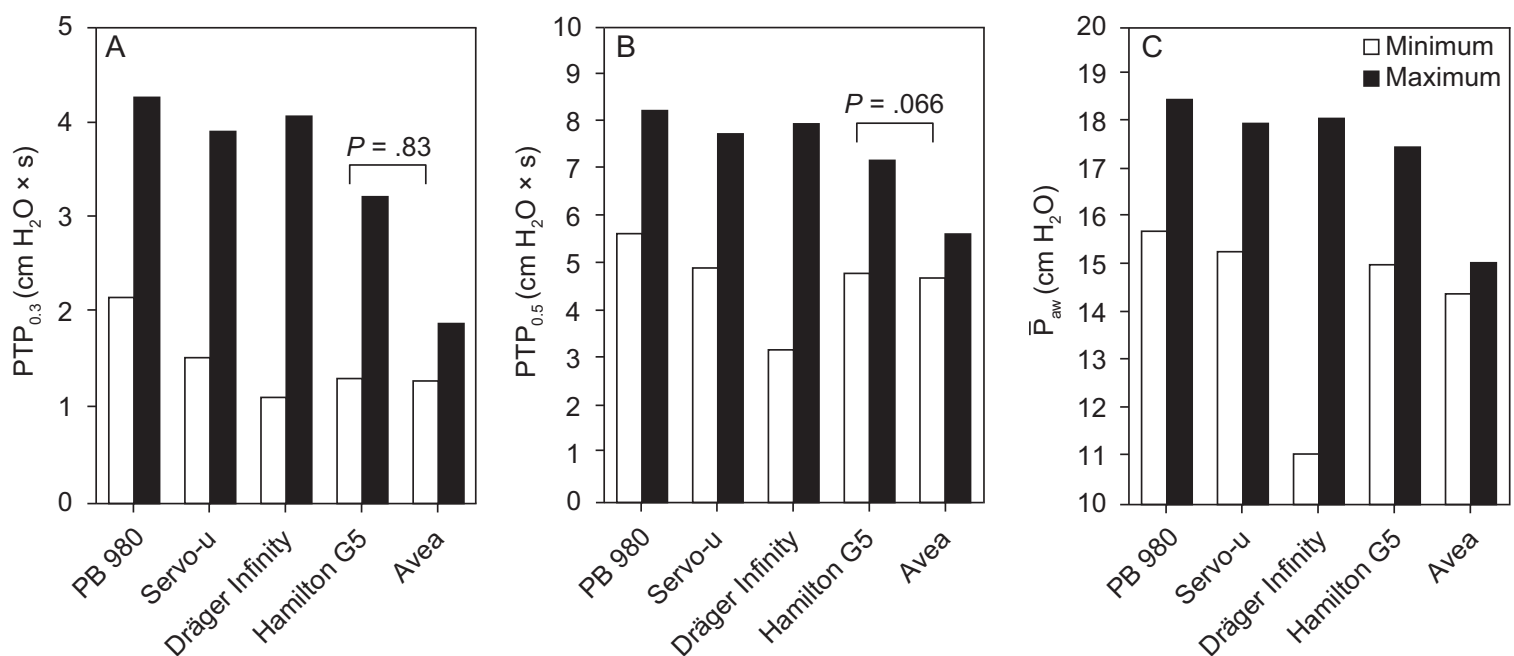

Fig. 4. Pressure-time products (PTPs) of airway pressure $\left(P_{\text {aw }}\right)$ at $0.3 \mathrm{~s}(\mathrm{~A})$ and $0.5 \mathrm{~s}(\mathrm{~B})$ from the beginning of the inspiratory phase and mean inspiratory pressure $(C)$ corresponding to the maximum and minimum pressurization ramp settings at the strong inspiratory effort level. Because of the narrow distribution range for each setting, the graphs only exhibit the mean values for each setting. Significant differences were observed among the ventilators at both pressurization ramp settings. Significant differences were observed between the combinations of ventilators using post hoc analysis, except for the combinations where $P>.05$ are shown.
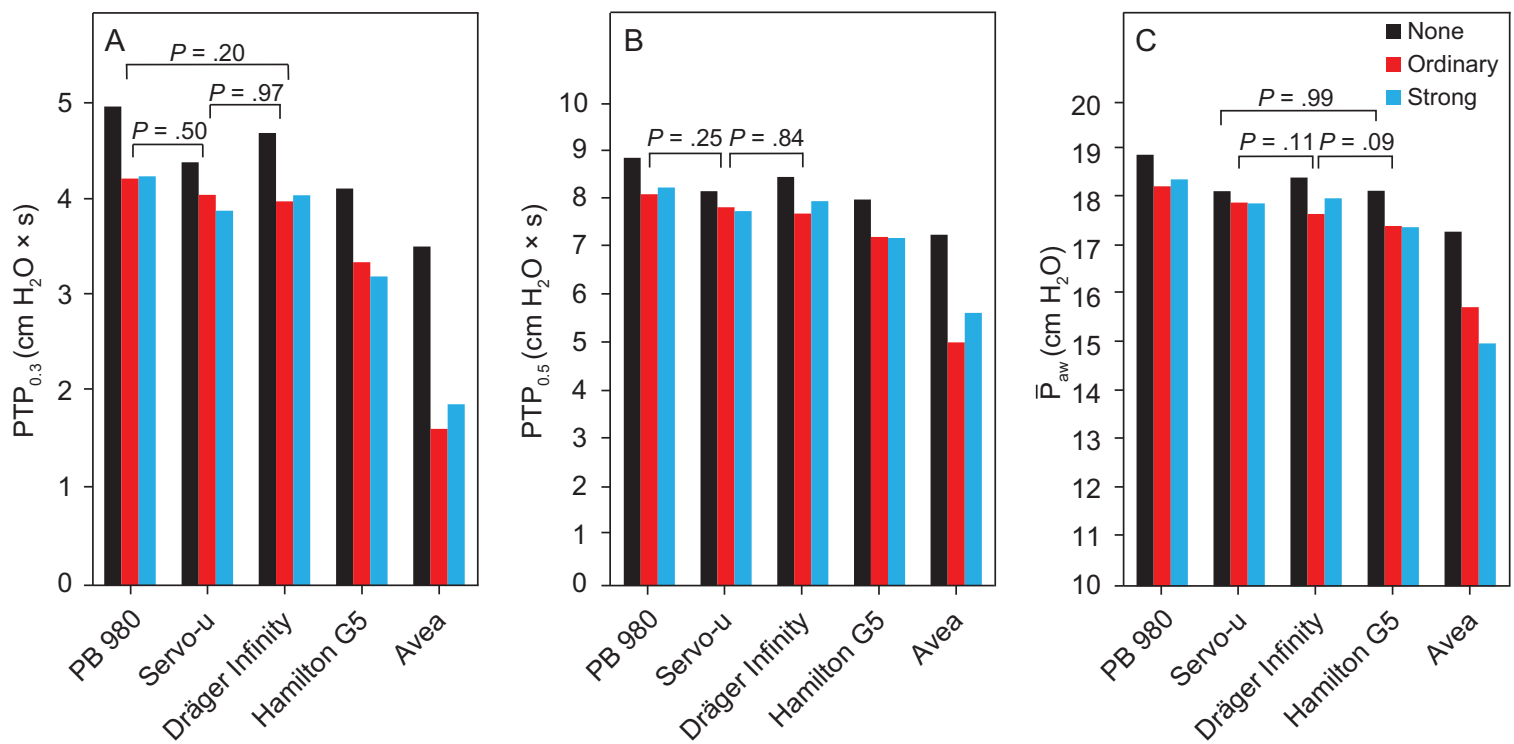

Fig. 5. Pressure-time products (PTPs) of airway pressure $\left(P_{a w}\right)$ at $0.3 \mathrm{~s}(A)$ and $0.5 \mathrm{~s}(\mathrm{~B})$ from the beginning of the inspiratory phase and mean airway pressure $(C)$ corresponding to the maximum pressurization ramp settings at none, ordinary, and strong inspiratory effort levels. Because of the narrow distribution range for each setting, the graphs only exhibit the mean values for each setting. Significant differences were observed among the ventilators at each inspiratory effort. Significant differences were observed between the combinations of ventilators using post hoc analysis, except for the combinations where $P>.05$ are shown.

settings and did not examine the effects of variability in pressurization ramp settings, ${ }^{10-14}$ knowledge about pressurization ramp settings is limited.

Inspiratory pressurization levels were adjusted by changing pressurization ramp settings. We compared the inspiratory pressurization, including the adjustment of the pressurization ramp settings. The adjustable ranges of $\mathrm{PTP}_{0.3}$ and $\mathrm{PTP}_{0.5}$ differed among the ventilators, as did the scale of pressurization ramp settings, which is demonstrated by percentage in the PB 980 ventilator, rise time in the Evita Infinity V500, Servo-u, and Hamilton G5 ventilators; and an arbitrary unit in the Avea ventilator. In addition, the inspiratory pressurization of 3 ventilators was not the same even with the same setting of rise time. Therefore, physicians must adjust the actual pressurization levels according to the graphical airway pressure wave. 
The differences between ventilators with respect to the characteristics of pressurization were considered to be related to be the differences in $\dot{V}_{\max }$ and $\mathrm{T}_{\max }$. The response curves of $\dot{V}_{\max }$ and $\mathrm{T}_{\max }$ against the pressurization ramp settings at the different inspiratory effort levels were different among the ventilators. Further precise examination is needed to clarify these aspects in a future study.

$\mathrm{V}_{\mathrm{T}}$ was not largely influenced by the pressurization ramp settings except with the Evita Infinity V500 ventilator. The $\mathrm{PTP}_{0.3}, \mathrm{PTP}_{0.5}$, and $\overline{\mathrm{P}}_{\mathrm{aw}}$ of the Evita Infinity V500 machine tended to be lower than those of the other ventilators at the minimum pressurization ramp setting. The adjustable ranges of $\mathrm{PTP}_{0.3}, \mathrm{PTP}_{0.5}$, and $\overline{\mathrm{P}}_{\mathrm{aw}}$ for the Evita Infinity V500 tended to be larger than those of others.

Default pressurization ramp settings by the manufactures were calibrated to $50 \%$ in the PB 980 , to $0.15 \mathrm{~s}$ in the Servo-u, to $0.2 \mathrm{~s}$ in the Evita Infinity V500, to $0.05 \mathrm{~s}$ in the Hamilton G5, and to 1 arbitrary unit in the Avea. The approximate levels of the parameters are presented in Figure 3. The actual pressurization was not largely different among these ventilators. The actual pressurization with the PB 980, Servo-u, Evita Infinity V500, and Hamilton G5 ventilators tended to be larger than that of the Avea machine. In addition, physicians can increase $\mathrm{PTP}_{0.3}, \mathrm{PTP}_{0.5}$, and $\overline{\mathrm{P}}_{\mathrm{aw}}$ by setting the pressurization ramp at higher levels in the PB 980, Servo-u, and Evita Infinity V500 ventilators because the more recently developed ventilators have wider adjustable ranges of pressurization.

Previous studies have examined the inspiratory pressurization function of ventilators in the pressure support ventilation mode. The inspiratory assist function of pressure support ventilation is affected not only by the initial inspiratory flow levels but also by the inspiratory termination criteria, which have been shown to affect the inspiratory time. ${ }^{4,17}$ Therefore, we used assist-control to PC-CMV mode evaluate only the inspiratory pressurization function of the ventilators.

One important limitation of this study is that it was performed on a lung model instead of on patients. It is possible that the performance of ventilators in patients differs from that observed in this study. The advantage of the lung model is that the mechanical characteristics could be standardized and reproduced. The ability to simulate spontaneous breathing with precisely calibrated patterns in the lung model allowed different ventilators to be tested under identical conditions. However, it is clear that differences may exist in actual conditions. We did not simulate and evaluate expiratory efforts, which are normally present in patients with a high inspiratory effort. Further study is needed to evaluate the clinical relevance of pressurization ramp settings in patients on mechanical ventilation.

\section{Conclusion}

With recently developed ICU ventilators, inspiratory pressurization exhibited a proportional increase with increases in pressurization ramp settings. Inspiratory pressurization at ordinary and strong effort levels did not differ largely among the new ventilators. The adjustable ranges of pressurization vary among the different types of ventilators. The actual absolute inspiratory pressurization in the assisted pressure controlled ventilation mode differed among the ventilators, even at similar pressurization ramp settings. Although pressurization was amenable to control by adjusting pressurization ramp settings, users should be mindful of the differences in the pressurization ramp settings for different ventilators.

\section{REFERENCES}

1. Thille AW, Rodriguez P, Cabello B, Lellouche F, Brochard L. Patient-ventilator asynchrony during assist mechanical ventilation. Intensive Care Med 2006;32(10):1515-1522.

2. Chao DC, Scheinhorn DJ, Stearn Hassenpflug M. Patient-ventilator trigger asynchrony in prolonged mechanical ventilation. Chest 1997; 112(6): 1592-1599.

3. Chiumello D, Pelosi P, Croci M, Bigatello LM, Gattinoni L. The effects of pressurization rate on breathing pattern, work of breathing, gas exchange, and patient comfort in pressure support ventilation. Eur Respir J 2001;18(1):107-114.

4. MacIntyre NR, Ho LI. Effects of initial flow rate and breath termination criteria on pressure support ventilation. Chest 1991;99(1):134-138.

5. Mancebo J, Amaro P, Mollo JL, Lorino H, Lemarie F, Brochard L. Comparison of the effects of pressure support ventilation delivered by three different ventilators during weaning from mechanical ventilation. Intensive Care Med 1995;21(11):913-919.

6. Chiumello D, Pelosi P, Taccone P, Slutsky A, Gattinoni L. Effect of different inspiratory rise time and cycling off criteria during pressure support ventilation in patients recovering from acute lung injury. Crit Care Med 2003;31(11):2604-2610.

7. Bonmarchand G, Chevron V, Chopin C, Jusserand D, Girault C, Moritz F, et al. Increased initial flow rate reduces inspiratory work of breathing during pressure support ventilation in patients with exacerbation of chronic obstructive pulmonary disease. Intensive Care Med 1996;22(11):1147-1154.

8. Bonmarchand G, Chevron V, Menard JF, Girault C, Moritz-Berthelot F, Pasquis $\mathrm{P}$, et al. Effect of pressure ramp slope values on the work of breathing during pressure support ventilation in restrictive patients. Crit Care Med 1999;27(4):715-722.

9. Cox D, Tinloi SF, Farrimond JG. Investigation of the spontaneous modes of breathing of different ventilators. Intensive Care Med 1988; 14(5):532-537.

10. Tassaux D, Strasser S, Fonseca S, Dalmas E, Jolliet P. Comparative bench study of triggering, pressurization, and cycling between the home ventilator VPAP II and theree ICU ventilators. Intensive Care Med 2002;28(9):1254-1261. 
11. Richard JC, Carlucci A, Breton L, Langlais N, Jaber S, Maggiore S, et al. Bench testing of pressure support ventilation with three different generations of ventilators. Intensive Care Med 2002;28(8):1049-1057.

12. Batitisi A, Tassaux D, Janssens JP, Michotte JB, Jaber S, Jolliet P. Performance characteristics of 10 home mechanical ventilators in pressure-support mode: a comparative bench study. Chest 2005;127(5):1784-1792.

13. Jaber S, Tassaux D, Sebbane M, Pouzeratte Y, Battisti A, Capdevila $\mathrm{X}$, et al. Performance characteristics of five new anesthesia ventilators in pressure-support mode: a comparative bench study. Anesthesiology 2006;105(7):944-952.

14. Thille AW, Lyazidi A, Richard JC, Galia F, Brochard L. A bench study of intensive-care-unit ventilators: new versus old and tubinebased versus compressed gas-based ventilators. Intensive Care Med 2009;35(8):1368-1376.
15. Boussen S, Gainnier M, Michelet P. Evaluation of ventilators used during transport of critically ill patients: a bench study. Respir Care 2013;58(11):1911-1922.

16. Brochard L, Lellouche F. Pressure support ventilation. In: Tobin MJ. Principles and practice of mechanical ventilation, 3rd ed. New York: McGraw Hill Medical; 2013.

17. Williams P, Kratohvil J, Ritz R, Hess DR, Kacmarek RM. Pressure support and pressure assist/control: are there differences? An evaluation of the newest intensive care unit ventilators. Respir Care 2000;45(10):1169-1181.

18. Katz JA, Kraemer RW, Gjerde GE. Inspiratory work and airway pressure with continuous positive airway pressure delivery systems. Chest 1985;88(4):519-536.

This article is approved for Continuing Respiratory Care Education credit. For information and to obtain your CRCE

(free to AARC members) visit

www.rcjournal.com 